\title{
Plantas Trepadeiras no Jardim Botânico de Porto Alegre, Rio Grande do Sul, Brasil: florística e chaves de identificação baseadas em caracteres vegetativos
}

\author{
Willian Souza Piovesani ${ }^{1, *}$ (1) \& Priscila Porto Alegre Ferreira ${ }^{2}$ \\ 'Universidade Federal do Rio Grande do Sul, Avenida Bento Gonçalves, n 9.500, Agronomia, 90650-001, \\ Porto Alegre, Rio Grande do Sul, Brasil \\ *Autor para correspondência: willianpiovesani@hotmail.com \\ ${ }^{2}$ Secretaria do Meio Ambiente e Infraestrutura do Rio Grande do Sul, Jardim Botânico de Porto Alegre, Seção de Coleções, \\ Rua Dr. Salvador França, n 1427, 90690-000 Porto Alegre, Rio Grande do Sul, Brasil.
}

Submetido em 23.IX.2021

Aceito em 20.X.2021

DOI 10.21826/2446-82312021v76e2021024

\begin{abstract}
RESUMO - O Jardim Botânico de Porto Alegre (JBPA) atua na conservação da flora nativa no Rio Grande do Sul e representa uma das principais áreas verdes da cidade. Através de coletas periódicas, foi realizado o levantamento florístico das plantas trepadeiras com ocorrência espontânea no JBPA. Para cada espécie, foram registrados os atributos hábito, mecanismo de escalada e síndrome de dispersão. São apresentadas chaves de identificação para as espécies baseadas em caracteres vegetativos. Foram registradas 81 espécies, sendo oito exóticas, pertencentes a 58 gêneros e 30 famílias. As três famílias mais ricas foram Apocynaceae, Asteraceae e Convolvulaceae com 11, nove e sete espécies, respectivamente. Há 42 trepadeiras herbáceas e 39 lenhosas, das quais o mecanismo de escalada mais frequente é o volúvel e a síndrome de dispersão a anemocoria. O atributo mecanismo de escalada mostra-se relacionado ao hábito, ao passo que a síndrome de dispersão não apresenta relação com o mesmo. Evidencia-se que o JBPA abriga $16 \%$ das espécies de trepadeiras nativas no estado, o que ressalta a importância dessa pequena área verde urbana para a conservação da flora.
\end{abstract}

Palavras-chave: área verde urbana, conservação, lianas

ABSTRACT - Climbing Plants in the Porto Alegre Botanical Garden, Rio Grande do Sul, Brazil: floristics and identification keys based on vegetative characters. The Porto Alegre Botanical Garden (JBPA) aims at the conservation of native flora in Rio Grande do Sul and represents one of the main green areas in the city. Through periodic collections, we made a floristic inventory of the naturally occurring climbers in JBPA. For each one of the species, the attributes growth form, climbing mechanism and dispersal syndrome were described. Identification keys for species based on vegetative characters are presented. We recorded 81 species, of which eight are exotic, belonging to 58 genera and 30 families. The three richest families were Apocynaceae, Asteraceae and Convolvulaceae with 11, nine and seven species, respectively. There are 42 herbaceous and 39 woody climbers, of which the most frequent climbing mechanism is the twiner and the dispersal syndrome is the anemochory. The climbing mechanism attribute is associated with growth form, while dispersal syndrome is not. This study highlights that the JBPA shelters $16 \%$ of the native climbers in the state, which emphasizes the importance of that small urban green area for the conservation of flora.

Keywords: conservation, lianas, urban green areas

\section{INTRODUÇÃO}

As trepadeiras são plantas que germinam no solo, mantêm-se enraizadas durante todo seu ciclo de vida e apresentam crescimento em altura dependente de sustentação mecânica (Darwin 1865, Gentry 1991, Durigon et al. 2009). Podem ser lenhosas ou herbáceas e apresentar ou não estruturas especializadas para escalar os suportes, por exemplo, gavinhas ou raízes adesivas. São geralmente classificadas em dois grandes grupos, de acordo com o hábito: trepadeiras herbáceas ou lenhosas - as lianas (Gentry 1991, Sperotto et al. 2020). As trepadeiras herbáceas têm caules delgados ou sublenhosos e geralmente se desenvolvem em áreas sujeitas a distúrbios e bordas de florestas. Já as lianas têm caules de maior diâmetro e são capazes de crescer no interior e atingir o dossel de florestas maduras (Gentry 1991).

As plantas trepadeiras são importantes componentes da flora global com participação expressiva na diversidade e dinâmica das comunidades vegetais. A sua contribuição em termos de diversidade, abundância e estrutura é maior em florestas tropicais, onde chegam a alcançar $25 \%$ da riqueza e até $40 \%$ da biomassa foliar (Gentry 1991, Schnitzer \& Bongers 2002). Como consequência, a maior parte do conhecimento existente é derivada de estudos realizados nesse tipo de vegetação. De fato, há uma diminuição da riqueza de trepadeiras com o aumento da latitude (Gentry 1991, Schnitzer 2005). Contudo, em latitudes elevadas, a riqueza das trepadeiras herbáceas aumenta em relação às lenhosas (Gallagher \& Leishman 2014), assumindo 
aquelas um papel importante no funcionamento de florestas subtropicais e temperadas e em áreas campestres (CarrascoUrra \& Gianoli 2009, Durigon et al. 2014, Durigon et al. 2019).

Estudos focados nas plantas trepadeiras têm aumentado apenas nas últimas duas décadas no Rio Grande do Sul e em zonas extratropicais de modo geral. No estado, há os trabalhos de Venturi (2000), Durigon et al. (2009), Durigon \& Waechter (2011), Seger \& Hartz (2014), Guerra et al. (2015) e Seger et al. (2017). Em uma ampla revisão das espécies trepadeiras nativas no RS, Durigon et al. (2019) confirmaram 448 espécies, o que representa cerca de $10 \%$ da flora vascular do estado (Flora do Brasil 2020). Essa proporção se assemelha às estimativas de Gentry (1991) para dados oriundos do hemisfério norte. Contudo, essa riqueza pode estar subestimada devido ao número reduzido de trabalhos com essa forma de vida em zonas subtropicais/ temperadas, onde as trepadeiras herbáceas assumem relevante contribuição florística, chegando a ultrapassar o número de lianas na América do Sul extratropical (Durigon et al. 2014).

Mesmo com o aumento na publicação de trabalhos florísticos envolvendo trepadeiras no Brasil, especialmente na última década, são raros os estudos que apresentam chaves de identificação, e ainda mais incipientes os que apresentam chaves baseadas exclusivamente em caracteres vegetativos (Udulutsch et al. 2010, Carneiro \& Vieira 2012, Guerra et al. 2015). A grande vantagem de uma chave de identificação baseada nesses caracteres é que possibilita o reconhecimento de espécies em qualquer época do ano, independente da presença de flores e/ou frutos, sendo de extrema valia para utilização no campo. Na literatura, a fonte mais completa que abrange a identificação baseada em aspectos não-reprodutivos de trepadeiras é o "Guia de Campo para as Famílias e Gêneros de Plantas Lenhosas do Noroeste da América do Sul" (Gentry 1993), focado nas espécies da região Amazônica. Devido à carência já mencionada de estudos centrados na região extratropical, materiais de fácil utilização para o reconhecimento da flora são muito necessários.

Jardins botânicos são importantes locais para a conservação da flora no mundo, papel que vem se tornando central frente à crescente extinção da biodiversidade (Barnosky et al. 2011, Powledge 2011, Heywood et al. 2017). A conservação ex situ figura como a estratégia amplamente utilizada pelos jardins botânicos para a conservação da flora, que consiste em manter os exemplares fora de seu habitat, em condições de cultivo ou armazenados e propagados em bancos de germoplasma. De maneira paralela, a conservação in situ tem por objetivo manter as espécies em seu ambiente natural de ocorrência, o que pode ser efetuado dentro dos limites da área do próprio jardim botânico ou em reservas administradas pelo mesmo (Maxted et al. 1997).

O Jardim Botânico de Porto Alegre (JBPA) tem ambas as estratégias definidas em suas diretrizes, priorizando a conservação das espécies nativas no Rio Grande do Sul
(FZBRS 2014). Além disso, presta serviços educacionais, culturais e ambientais à população, sendo declarado Patrimônio Cultural do estado do Rio Grande do Sul (Rio Grande do Sul 2003). O JBPA é um dos poucos jardins botânicos do Brasil enquadrados na categoria A (MMA 2003), pelo cumprimento de uma série de requisitos envolvendo estrutura adequada para pesquisa e publicações científicas, manutenção de corpo técnico especializado e de cursos voltados ao público externo.

Jardins botânicos, assim como parques e praças arborizados, são considerados áreas verdes urbanas. Interferem diretamente na qualidade de vida da população por meio das funções sociais, ecológicas, estéticas e educativas que exercem, atuando como amenizadoras das consequências negativas da urbanização. Dentre os benefícios providos por essas áreas estão o controle da poluição do ar e acústica, estabilização de superfícies por meio da fixação do solo pelas raízes das plantas, abrigo à fauna, proteção das nascentes e dos mananciais, equilíbrio do índice de umidade do ar, recreação, educação ambiental e a conservação da biodiversidade local (Bargos \& Matias 2011). A área de pesquisa que busca compreender os sistemas naturais dentro do âmbito urbano, conhecida como Ecologia Urbana, avançou nas últimas décadas com a integração de diferentes perspectivas e se tornou primordial para a humanidade (Tanner et al. 2014, McPhearson et al. 2016). Para que possamos valorizar as áreas verdes de nossa cidade, é fundamental conhecer as formas de vida ali residentes, criando meios para que a população se integre desse conhecimento.

Bueno \& Martins (1986) realizaram o primeiro levantamento florístico no JBPA, incluindo as fanerógamas herbáceas e arbustivas de crescimento espontâneo nas áreas não ajardinadas, e identificaram 279 espécies. Dresseno \& Overbeck (2013) analisaram a estrutura e a composição do relicto de campo que compõe a Zona de Conservação in situ e encontraram 183 espécies nativas. Os autores salientaram o alto valor de conservação dessa área que deve ser considerada prioritária, por abrigar várias espécies endêmicas do bioma Pampa. Rolim et al. (2014) analisaram a composição e a estrutura da vegetação campestre em duas áreas distintas do parque, com o registro de 125 espécies. E, mais recentemente, Soares \& Fagundes (2020) listaram 35 espécies de epífitos vasculares na área do JBPA. Embora esses estudos tenham sido essenciais para o conhecimento da flora nativa da área, existe uma lacuna no conhecimento de outras formas de vida, como é o caso das plantas trepadeiras.

O objetivo deste estudo foi identificar as espécies de plantas trepadeiras ocorrentes de forma espontânea no Jardim Botânico de Porto Alegre, fornecendo informações sobre os atributos funcionais das espécies (hábito, mecanismo de escalada e síndrome de dispersão) e chaves de identificação baseadas em caracteres vegetativos, contribuindo para o conhecimento da flora dessa importante área verde do município. 


\section{MATERIAL E MÉTODOS}

O trabalho foi realizado no Jardim Botânico de Porto Alegre (JBPA), localizado no bairro Jardim Botânico, zona leste do município de Porto Alegre, Rio Grande do Sul, entre as latitudes $30^{\circ} 02^{\prime} 55^{\prime \prime} \mathrm{S} \mathrm{e} 30^{\circ} 03^{\prime} 18^{\prime \prime} \mathrm{S}$ e as longitudes $51^{\circ} 10^{\prime} 50^{\prime \prime} \mathrm{W}$ e $51^{\circ} 10^{\prime} 19^{\prime \prime} \mathrm{W}$ (Fig. 1).

Porto Alegre situa-se na região fisiográfica da Depressão Central, em contato com as regiões da Encosta da Serra do Sudeste e do Litoral (Pacheco 1956), na latitude de transição entre os biomas Pampa e Mata Atlântica (IBGE 2012). A cidade abriga 44 morros graníticos oriundos da formação geológica da Serra do Sudeste, os quais são distribuídos em sentido nordeste-sudoeste (Setubal et al. 2011). A cobertura vegetal é florestal nas encostas e campestre nos topos, o que torna esses ambientes verdadeiros mosaicos de elevada riqueza específica (Hasenack et al. 2008, Setubal et al. 2011). O clima é classificado como subtropical úmido - Cfa, segundo Köppen-Geiger (Kottek et al. 2006). A temperatura e a precipitação médias mensais são de $17,7^{\circ} \mathrm{C}$ e 104,7 mm, respectivamente (INMET 2019).

A área atual do JBPA é de 36 ha e a vegetação natural é composta por campos e florestas secundárias. A Zona de Conservação in situ consiste em um relicto de campo nativo de aproximadamente $1,5 \mathrm{ha}$, limitado por fragmentos florestais e, ao sul, pelo terreno do Hospital São Lucas da Pontifícia Universidade Católica do Rio Grande do Sul
(PUCRS). Aárea é cercada e resguardada de acesso público, sendo somente permitida a pesquisa nesse local. As espécies pioneiras e invasoras são retiradas, a fim de se evitar o adensamento natural da floresta sobre o campo (FZBRS 2014). O trabalho foi realizado nas áreas de vegetação natural e na Zona de Conservação in situ (Figs. 1 e 2), considerando todas as espécies trepadeiras de ocorrência espontânea. As demais áreas são ajardinadas e abrigam os prédios e as coleções ex situ do arboreto, onde há espécies de trepadeiras plantadas e/ou catalogadas nas coleções.

A amostragem foi realizada no período de janeiro de 2017 a novembro de 2018 pelo método do caminhamento exploratório (adaptado de Filgueiras et al. 1994). Todo material fértil (com flor e/ou fruto) encontrado foi fotografado e coletado durante expedições quinzenais. As coletas foram herborizadas e identificadas com auxílio de bibliografia específica, comparação com material dos herbários HAS e ICN, consulta a bases de dados (speciesLink 2021 e REFLORA 2021) e contato com especialistas. As amostras foram depositadas no Herbário HAS do Museu de Ciências Naturais (MCN). O sistema de classificação adotado para as famílias seguiu a última proposta do Angiosperm Philogeny Group (APG IV 2016) e a nomenclatura das espécies seguiu a adotada por especialistas, constantemente atualizada na Flora do Brasil (Flora do Brasil 2020) e no International Plant Names Index (IPNI 2020).

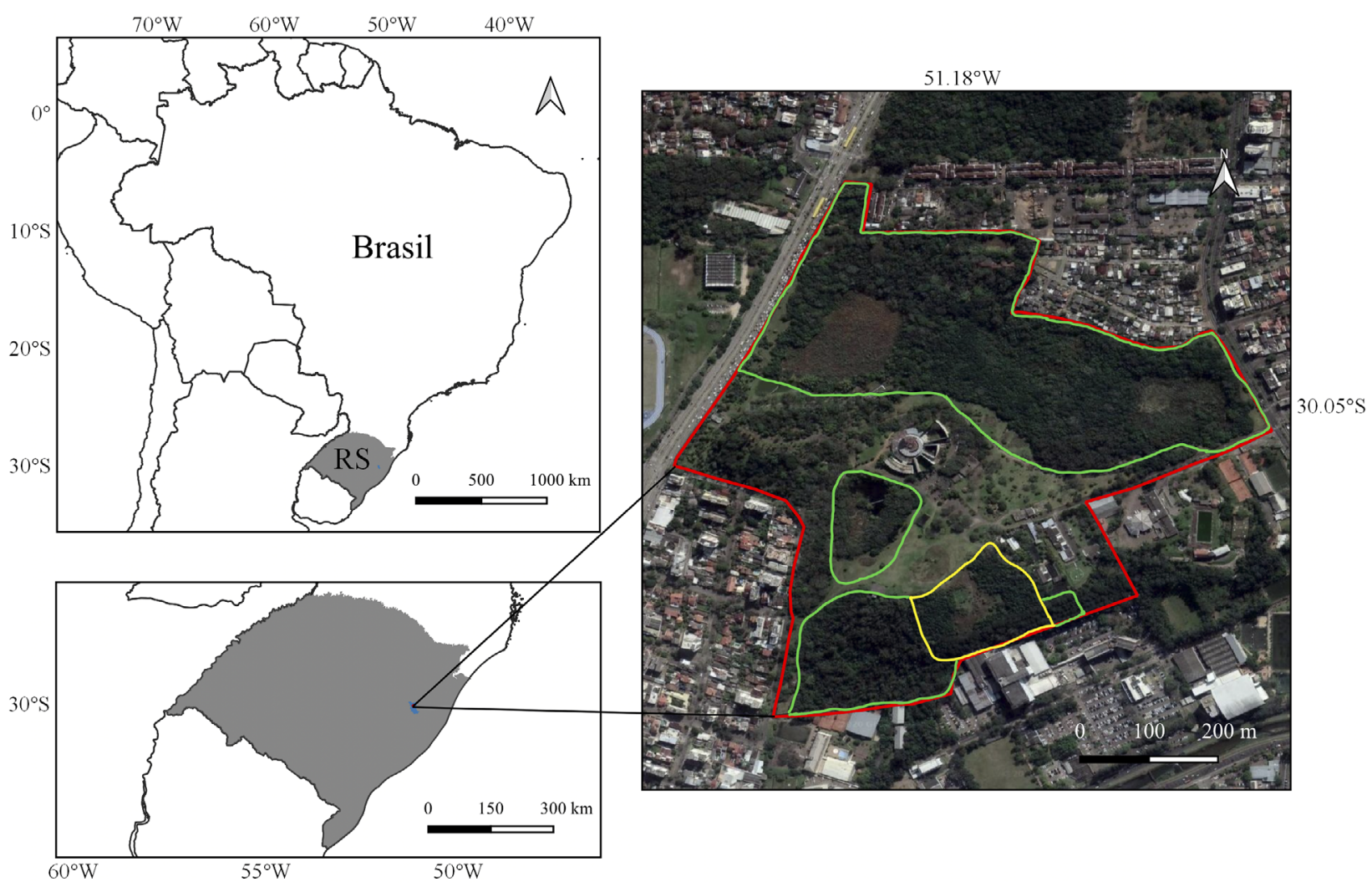

Figura 1. Mapa de localização e áreas de vegetação amostradas no Jardim Botânico de Porto Alegre, RS, Brasil. Em vermelho, a delimitação do JBPA; em verde, áreas de vegetação natural; em amarelo, a Zona de Conservação in situ. 

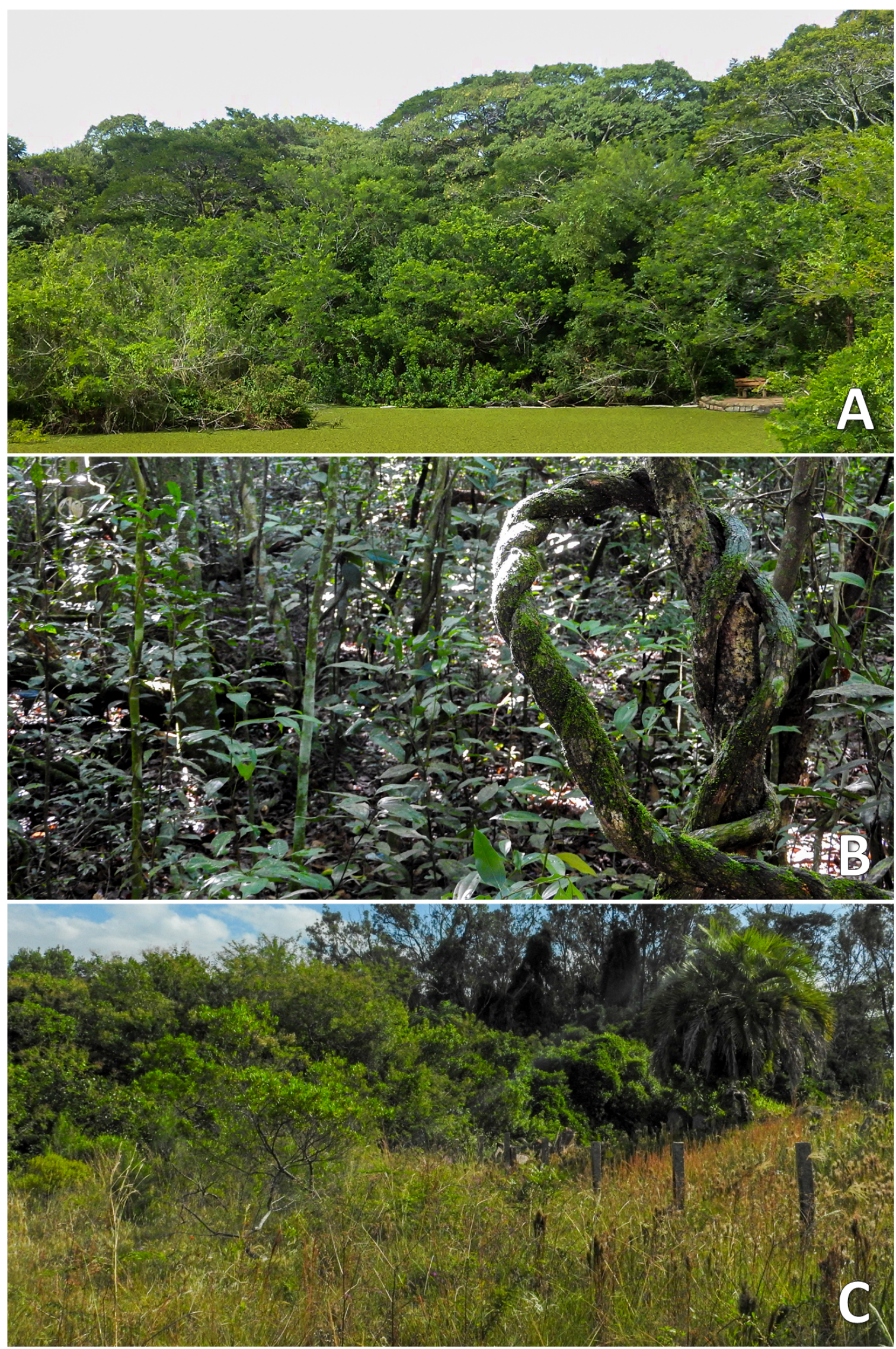

Figura 2. Ambientes de vegetação natural do Jardim Botânico de Porto Alegre. A. Aspecto geral da floresta secundária do entorno do lago de cima; B. Interior da floresta secundária do entorno do lago de cima; C. Campo nativo situado no interior da Zona de Conservação in situ. 
Foram consultadas as bases de dados e os herbários citados em busca de registros de espécimes coletados no JBPA. Quanto às espécies citadas em levantamentos florísticos anteriores, foram incluídas apenas as que possuem material-testemunho depositado em herbário, tendo sido este revisado.

As espécies foram classificadas quanto ao hábito, mecanismo de escalada e síndrome de dispersão. Quanto ao hábito, foram categorizadas em herbáceas ou lenhosas (Gentry 1991, Sperotto et al. 2020). Quanto ao mecanismo de escalada, utilizou-se a seguinte nomenclatura (Hegarty 1991): apoiante - apoia-se na vegetação adjacente, com ou sem estruturas como acúleos ou espinhos; volúvel - enrolase no suporte através dos ramos ou pecíolos; gavinhosa - possui gavinhas; e radicante - possui raízes adesivas. Quando a espécie apresenta mais de um mecanismo, apenas o principal foi considerado. Em relação à síndrome de dispersão, utilizou-se a seguinte classificação (adaptada de van der Pijl 1982): anemocórica - diásporos dispersos pelo vento; autocórica - apresenta algum mecanismo de autodispersão dos diásporos, por exemplo, abertura explosiva do fruto; barocórica - diásporos dispersos pelo seu próprio peso; e zoocórica - diásporos dispersos por animais.

Foram calculadas as relações de associação entre os atributos através do qui-quadrado, buscando verificar se o hábito (herbáceo ou lenhoso) apresenta interdependência com os atributos mecanismo de escalada e síndrome de dispersão na comunidade estudada. Todas as análises foram realizadas no ambiente R v3.6.0 (R Developmental Core Team 2019). Os mapas foram construídos no software livre QGIS v3.10.5 (QGIS 2021).

As chaves de identificação foram construídas utilizando somente caracteres vegetativos e são do formato indentado. Foi elaborada uma pequena chave, a qual leva em consideração primariamente o mecanismo de escalada das espécies e que funciona como um índice para as chaves de identificação específicas.

\section{RESULTADOS}

Foram registradas 81 espécies de plantas trepadeiras de ocorrência espontânea no JBPA, pertencentes a 30 famílias e 58 gêneros, sendo oito (10\%) espécies exóticas no RS. As famílias Apocynaceae (11 espécies), Asteraceae (nove), Convolvulaceae (sete), Bignoniaceae e Fabaceae (seis cada) e Passifloraceae (cinco) contribuíram com $54 \%$ da riqueza total. Adicionalmente, 16 famílias (53\%) contribuíram com apenas uma espécie. Os gêneros mais representativos foram Mikania (sete espécies), Ipomoea e Passiflora (cinco cada), perfazendo $21 \%$ da riqueza total (Tab. 1, Figs. 3, 4 e 5).

Tabela 1. Lista de espécies, hábito, mecanismo de escalada, síndrome de dispersão e voucher do herbário HAS para as espécies de plantas trepadeiras ocorrentes no Jardim Botânico de Porto Alegre, RS, Brasil. Hábito: H = herbáceo; L = lenhoso. Mecanismo de escalada: Apo = apoiante; Gav = gavinhosa; $\mathrm{Rad}=$ radicante; $\mathrm{Vol}=$ volúvel. Síndrome de dispersão: Ane $=$ anemocórica; Aut $=$ autocórica; Bar $=$ barocórica; Zoo $=$ Zoocórica. *Espécie exótica no Rio Grande do Sul.

\begin{tabular}{|c|c|c|c|c|}
\hline Família/espécies & Hábito & Mecanismo de escalada & Síndrome de dispersão & Voucher HAS \\
\hline \multicolumn{5}{|l|}{ ACANTHACEAE } \\
\hline Thunbergia alata Bojer ex Sims* & $\mathrm{H}$ & Vol & Aut & 94392 \\
\hline \multicolumn{5}{|l|}{ APOCYNACEAE } \\
\hline Araujia sericifera Brot. & $\mathrm{H}$ & Vol & Ane & 94316 \\
\hline Ditassa burchellii Hook. \& Arn. & $\mathrm{H}$ & Vol & Ane & 94306 \\
\hline Forsteronia glabrescens Müll.Arg. & $\mathrm{L}$ & Vol & Ane & 94310 \\
\hline Forsteronia leptocarpa A.DC. & $\mathrm{L}$ & Vol & Ane & 94309 \\
\hline Gonolobus parviflorus Decne. & $\mathrm{H}$ & Vol & Ane & 94318 \\
\hline Mandevilla pentlandiana (A.DC.) Woodson & $\mathrm{H}$ & Vol & Ane & 94331 \\
\hline Orthosia scoparia (Nutt.) Liede \& Meve & $\mathrm{L}$ & Vol & Ane & 94319 \\
\hline Orthosia urceolata E.Fourn. & $\mathrm{H}$ & Vol & Ane & 96083 \\
\hline Orthosia virgata E.Fourn. & $\mathrm{H}$ & Vol & Ane & 94308 \\
\hline Oxypetalum wightianum Hook. \& Arn. & $\mathrm{H}$ & Vol & Ane & 94332 \\
\hline Rhabdadenia madida Miers & $\mathrm{H}$ & Vol & Ane & 94311 \\
\hline \multicolumn{5}{|l|}{ ARISTOLOCHIACEAE } \\
\hline Aristolochia triangularis Cham. & $\mathrm{L}$ & Vol & Bar & 94334 \\
\hline \multicolumn{5}{|l|}{ ARALIACEAE } \\
\hline Hedera helix L.* & $\mathrm{L}$ & Rad & Zoo & 94221 \\
\hline \multicolumn{5}{|l|}{ ASPARAGACEAE } \\
\hline Asparagus setaceus (Kunth) Jessop* & $\mathrm{H}$ & Vol & Zoo & 94393 \\
\hline
\end{tabular}


Tabela 1. Cont.

\begin{tabular}{|c|c|c|c|c|}
\hline Família/espécies & Hábito & Mecanismo de escalada & Síndrome de dispersão & Voucher HAS \\
\hline \multicolumn{5}{|l|}{ ASTERACEAE } \\
\hline Baccharis anomala DC. & $\mathrm{L}$ & Apo & Ane & 94321 \\
\hline Calea pinnatifida Banks ex Steud. & $\mathrm{L}$ & Apo & Ane & 94322 \\
\hline Mikania cordifolia (L.f.) Willd. & $\mathrm{L}$ & Vol & Ane & 96079 \\
\hline Mikania glomerata Spreng. & $\mathrm{L}$ & Vol & Ane & 94326 \\
\hline Mikania hastato-cordata Malme & $\mathrm{H}$ & Vol & Ane & 94324 \\
\hline Mikania involucrata Hook. \& Arn. & $\mathrm{H}$ & Vol & Ane & 94330 \\
\hline Mikania laevigata Sch.Bip. ex Baker & $\mathrm{L}$ & Vol & Ane & 94331 \\
\hline Mikania micrantha Kunth & $\mathrm{H}$ & Vol & Ane & 94327 \\
\hline Mikania parodii Cabrera & $\mathrm{H}$ & Vol & Ane & 14143 \\
\hline \multicolumn{5}{|l|}{ BASELLACEAE } \\
\hline Anredera cordifolia (Tem.) Steenis & $\mathrm{H}$ & Vol & Zoo & 94335 \\
\hline \multicolumn{5}{|l|}{ BIGNONIACEAE } \\
\hline Amphilophium crucigerum (L.) L.G.Lohmann & $\mathrm{L}$ & Gav & Ane & 94340 \\
\hline Dolichandra unguis-cati (L.) L.G.Lohmann & $\mathrm{L}$ & Gav & Ane & 94339 \\
\hline Fridericia chica (Bonpl.) L.G.Lohmann & $\mathrm{L}$ & Gav & Ane & 94343 \\
\hline Podranea ricasoliana Sprague* & $\mathrm{L}$ & Apo & Ane & 94336 \\
\hline Pyrostegia venusta Miers & $\mathrm{L}$ & Gav & Ane & 96084 \\
\hline Tanaecium selloi (Spreng.) L.G.Lohmann & $\mathrm{L}$ & Gav & Ane & 94342 \\
\hline \multicolumn{5}{|l|}{ CACTACEAE } \\
\hline Pereskia aculeata Mill. & $\mathrm{L}$ & Apo & Zoo & 94345 \\
\hline \multicolumn{5}{|l|}{ CAPRIFOLIACEAE } \\
\hline Lonicera japonica Thunb.* & $\mathrm{L}$ & Vol & Zoo & 94346 \\
\hline \multicolumn{5}{|l|}{ CONVOLVULACEAE } \\
\hline Convolvulus crenatifolius Ruiz \& Pav. & $\mathrm{H}$ & Vol & Bar & 94305 \\
\hline Distimake dissectus (Jacq.) A.R. Simões \& Staples & $\mathrm{L}$ & Vol & Bar & 94304 \\
\hline Ipomoea alba $\mathrm{L}$. & $\mathrm{H}$ & Vol & Bar & 94222 \\
\hline Ipomoea cairica $(\mathrm{L}$.) Sweet & $\mathrm{H}$ & Vol & Bar & 96043 \\
\hline Ipomoea indica (Burm.) Merr. f. & $\mathrm{H}$ & Vol & Bar & 94302 \\
\hline Ipomoea nil (L.) Roth & $\mathrm{H}$ & Vol & Bar & 94223 \\
\hline Ipomoea triloba $\mathrm{L}$. & $\mathrm{H}$ & Vol & Bar & 94300 \\
\hline \multicolumn{5}{|l|}{ CUCURBITACEAE } \\
\hline Cayaponia martiana Cogn. & $\mathrm{H}$ & Gav & Zoo & 94347 \\
\hline Melothria cucumis Vell. & $\mathrm{H}$ & Gav & Zoo & 94224 \\
\hline \multicolumn{5}{|l|}{ DIOSCOREACEAE } \\
\hline Dioscorea bulbifera L.* & $\mathrm{H}$ & Vol & Ane & 94349 \\
\hline Dioscorea multiflora Mart. ex Griseb. & $\mathrm{H}$ & Vol & Ane & 94348 \\
\hline \multicolumn{5}{|l|}{ EUPHORBIACEAE } \\
\hline Dalechampia stenosepala Müll.Arg. & $\mathrm{H}$ & Vol & Bar & 96088 \\
\hline Tragia volubilis $\mathrm{L}$. & $\mathrm{H}$ & Vol & Bar & 94225 \\
\hline \multicolumn{5}{|l|}{ FABACEAE } \\
\hline Canavalia bonariensis Lindl. & $\mathrm{L}$ & Vol & Bar & 94351 \\
\hline Lathyrus crassipes Gillies ex Hook. \& Arn. & $\mathrm{H}$ & Gav & Aut & 10150 \\
\hline Leptospron adenanthum (G. Mey.) A. Delgado & $\mathrm{H}$ & Vol & Aut & 94356 \\
\hline $\begin{array}{l}\text { Macropsychanthus violaceus (Mart. ex Benth.) } \\
\text { L.P.Queiroz \& Snak }\end{array}$ & $\mathrm{L}$ & Vol & Bar & 94353 \\
\hline Macroptilium prostratum Urb. & $\mathrm{H}$ & Vol & Aut & 94355 \\
\hline Vicia angustifolia $\mathrm{L} . *$ & $\mathrm{H}$ & Gav & Aut & 94358 \\
\hline
\end{tabular}


Tabela 1. Cont

\begin{tabular}{|c|c|c|c|c|}
\hline Família/espécies & Hábito & Mecanismo de escalada & Síndrome de dispersão & Voucher HAS \\
\hline \multicolumn{5}{|l|}{ LOGANIACEAE } \\
\hline Strychnos brasiliensis Mart. & $\mathrm{L}$ & Apo & Zoo & 94360 \\
\hline \multicolumn{5}{|l|}{ MALPIGHIACEAE } \\
\hline Heteropterys aenea Griseb. & $\mathrm{L}$ & Vol & Ane & 94365 \\
\hline Heteropterys intermedia Griseb. & $\mathrm{L}$ & Vol & Ane & 94362 \\
\hline Heteropterys syringifolia Griseb. & $\mathrm{L}$ & Vol & Ane & 94361 \\
\hline Janusia guaranitica A.Juss. & $\mathrm{H}$ & Vol & Ane & 94363 \\
\hline \multicolumn{5}{|l|}{ MENISPERMACEAE } \\
\hline Cissampelos pareira L. & $\mathrm{H}$ & Vol & Zoo & 94366 \\
\hline \multicolumn{5}{|l|}{ NYCTAGINACEAE } \\
\hline Bougainvillea spectabilis Willd.* & $\mathrm{L}$ & Apo & Zoo & 94226 \\
\hline \multicolumn{5}{|l|}{ PASSIFLORACEAE } \\
\hline Passiflora alata Curtis & $\mathrm{L}$ & Gav & Zoo & 94371 \\
\hline Passiflora edulis Sims & $\mathrm{L}$ & Gav & Zoo & 94372 \\
\hline Passiflora misera Kunth & $\mathrm{H}$ & Gav & Zoo & 94369 \\
\hline Passiflora suberosa L. & $\mathrm{H}$ & Gav & Zoo & 94367 \\
\hline Passiflora tenuifila Killip & $\mathrm{H}$ & Gav & Zoo & 94370 \\
\hline \multicolumn{5}{|l|}{ POLYGONACEAE } \\
\hline Muehlenbeckia sagittifolia (Ortega) Meisn. & $\mathrm{L}$ & Vol & Zoo & 94373 \\
\hline \multicolumn{5}{|l|}{ ROSACEAE } \\
\hline Rubus urticifolius Poir. & $\mathrm{L}$ & Apo & Zoo & 96085 \\
\hline \multicolumn{5}{|l|}{ RUBIACEAE } \\
\hline Chiococca alba Hitchc. & $\mathrm{L}$ & Apo & Zoo & 94375 \\
\hline Galium hypocarpium Endl. ex Griseb. & $\mathrm{H}$ & Apo & Zoo & 94377 \\
\hline Guettarda uruguensis Cham. \& Schltdl. & $\mathrm{L}$ & Apo & Zoo & 94378 \\
\hline \multicolumn{5}{|l|}{ SAPINDACEAE } \\
\hline Cardiospermum halicacabum L. & $\mathrm{H}$ & Gav & Ane & 94381 \\
\hline Paullinia elegans Cambess. & $\mathrm{L}$ & Gav & Zoo & 94382 \\
\hline Serjania hebecarpa Benth. & $\mathrm{L}$ & Gav & Ane & 94379 \\
\hline Serjania laruotteana Cambess. & $\mathrm{L}$ & Gav & Ane & 94380 \\
\hline \multicolumn{5}{|l|}{ SMILACACEAE } \\
\hline Smilax campestris Griseb. & $\mathrm{H}$ & Gav & Zoo & 94383 \\
\hline Smilax cognata Kunth & $\mathrm{H}$ & Gav & Zoo & 94384 \\
\hline \multicolumn{5}{|l|}{ SOLANACEAE } \\
\hline Solanum laxum Spreng. & $\mathrm{H}$ & Vol & Zoo & 94385 \\
\hline \multicolumn{5}{|l|}{ TROPAEOLACEAE } \\
\hline Tropaeolum pentaphyllum Lam. & $\mathrm{H}$ & Vol & Zoo & 96086 \\
\hline \multicolumn{5}{|l|}{ VERBENACEAE } \\
\hline Lantana camara $\mathrm{L}$. & $\mathrm{L}$ & Apo & Zoo & 94387 \\
\hline \multicolumn{5}{|l|}{ VIOLACEAE } \\
\hline Anchietea pyrifolia (Mart.) G.Don & $\mathrm{L}$ & Vol & Ane & 94391 \\
\hline \multicolumn{5}{|l|}{ VITACEAE } \\
\hline Cissus verticillata (L.) Nicolson \& C.E. Jarvis & $\mathrm{L}$ & Gav & Zoo & 94389 \\
\hline Clematicissus striata (Ruiz \& Pav.) Lombardi & $\mathrm{L}$ & Gav & Zoo & 94390 \\
\hline
\end{tabular}



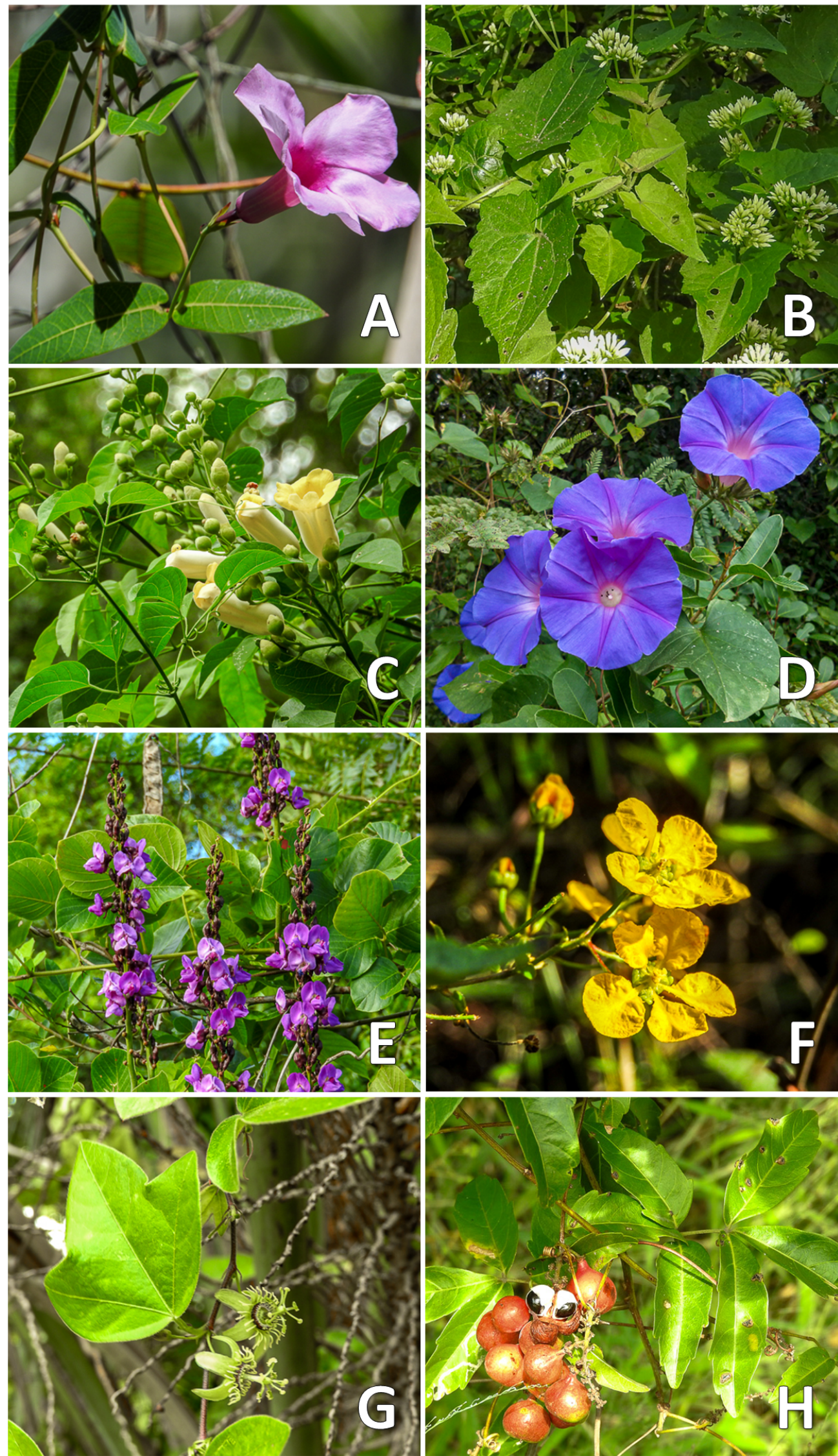

Figura 3. Representantes das famílias mais diversas encontradas na área de estudo. A. Rhabdadenia madida (Apocynaceae); B. Mikania micrantha (Asteraceae); C. Amphilophium crucigerum (Bignoniaceae); D. Ipomoea indica (Convolvulaceae); E. Macropsychanthus violaceus (Fabaceae); F . Janusia guaranitica (Malpighiaceae); G. Passiflora suberosa (Passifloraceae); H. Paullinia elegans (Sapindaceae). 

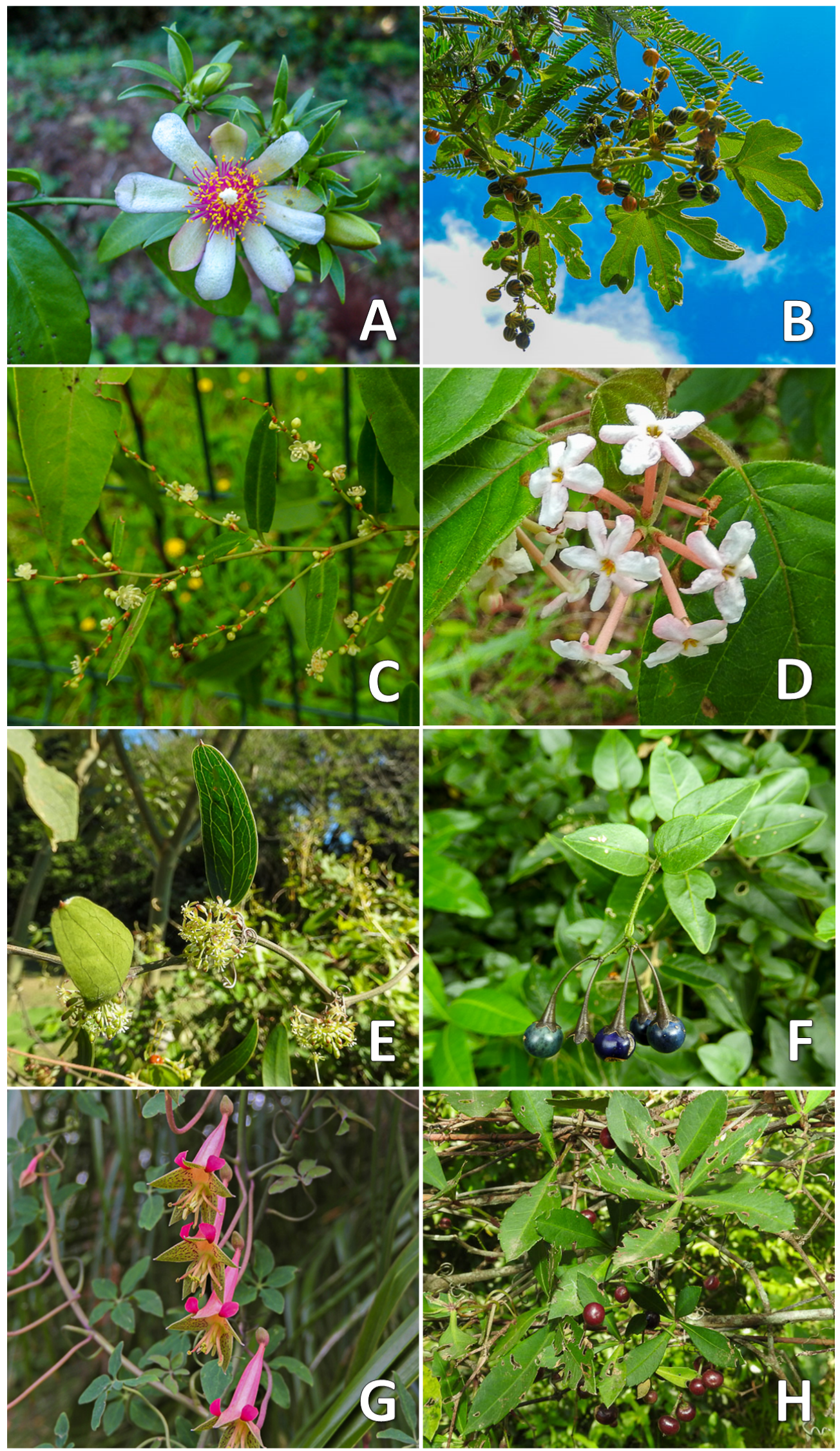

Figura 4. Representantes de outras famílias encontradas na área de estudo. A. Pereskia aculeata (Cactaceae); B. Cayaponia martiana (Cucurbitaceae); C. Muehlenbeckia sagittifolia (Polygonaceae); D. Guettarda uruguensis (Rubiaceae); E. Smilax campestris (Smilacaceae); F. Solanum laxum (Solanaceae); G. Tropaeolum pentaphyllum (Tropaeolaceae); H. Clematicissus striata (Vitaceae). 
Em relação ao hábito, há 42 trepadeiras herbáceas (52\%) e 39 lenhosas (48\%). Quanto ao mecanismo de escalada, 47 espécies são volúveis (58\%), 22 são gavinhosas (27\%), 11 são apoiantes (14\%) e apenas uma é radicante (1\%). Quanto à síndrome de dispersão, 36 espécies são anemocóricas (44\%), 28 são zoocóricas (35\%), 12 são barocóricas (15\%) e cinco são autocóricas (6\%) (Tab. 1).

Para as espécies da área de estudo, o atributo mecanismo de escalada é relacionado ao hábito $(\chi 2=13,24 ; \mathrm{p}=0,0041)$. Portanto, os atributos são interdependentes, indicando que trepadeiras herbáceas e lenhosas diferem quanto ao mecanismo de escalada. O mecanismo volúvel mostra-se mais associado às herbáceas do que às lianas, enquanto estas apresentam mais espécies apoiantes e gavinhosas (Fig. 6). Por outro lado, o atributo síndrome de dispersão não se relaciona com o hábito $(\chi 2=6,8189 ; \mathrm{p}=0,0779)$, assim, trepadeiras herbáceas e lenhosas não podem ser separadas de acordo com a síndrome de dispersão (Fig. 7).

Um total de seis chaves analíticas baseadas em caracteres vegetativos são apresentadas para auxiliar na identificação das espécies. Os principais caracteres utilizados são mecanismo de escalada e hábito, filotaxia, tipo e formato da folha, presença de látex, presença de acúleos ou espinhos, formato e localização da gavinha, e presença e formato das estípulas.

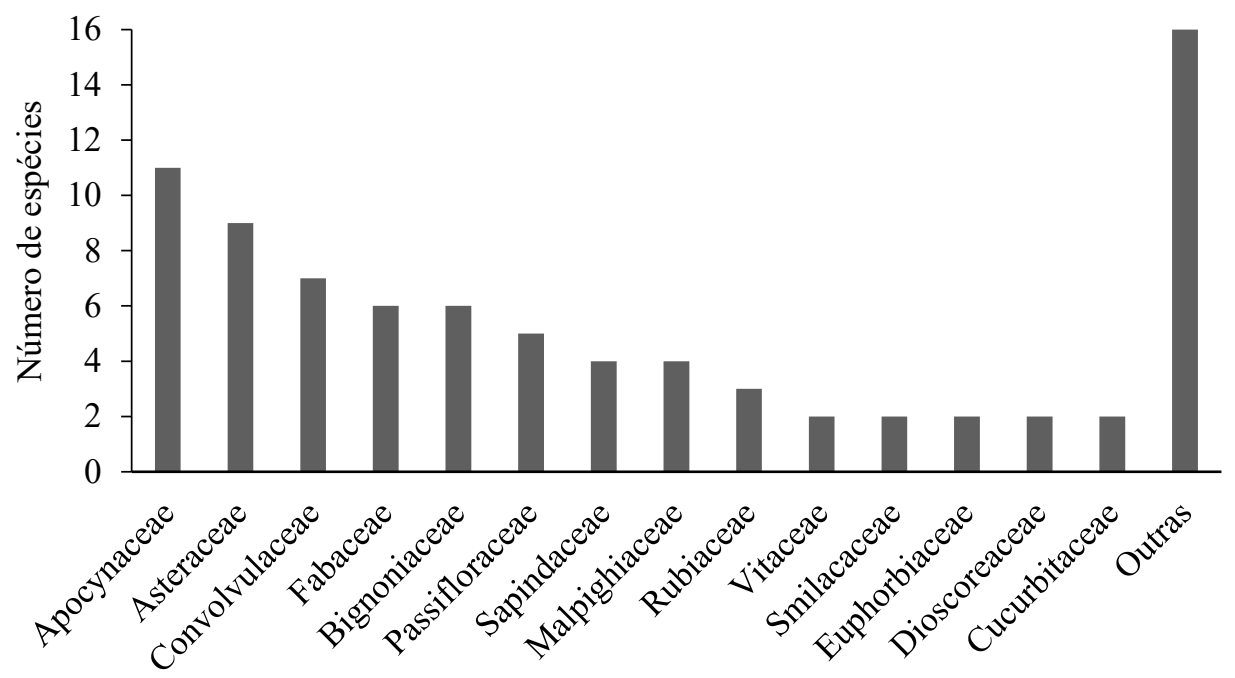

Figura 5. Riqueza das famílias de trepadeiras encontradas na área de estudo. "Outras” representa famílias com apenas uma espécie.

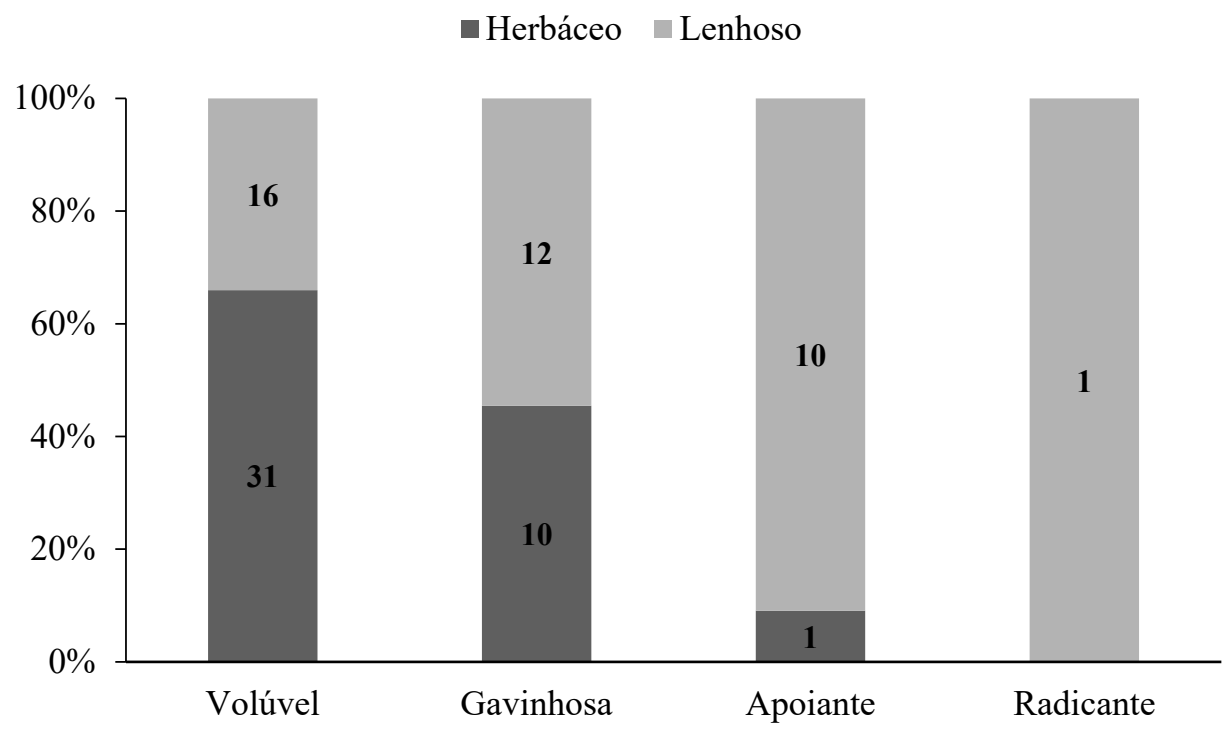

Figura 6. Relação entre o mecanismo de escalada e o hábito. Os números nas colunas indicam a riqueza. 


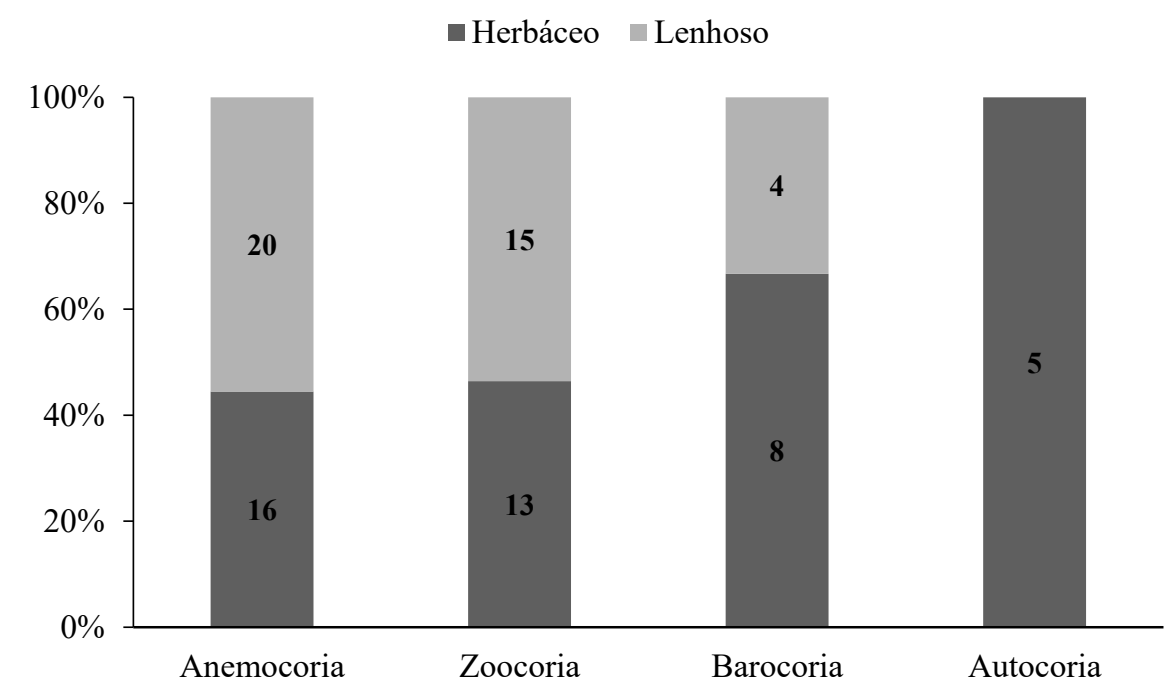

Figura 7. Relação entre a síndrome de dispersão e o hábito. Os números nas colunas indicam a riqueza.

\section{DISCUSSÃO}

Seis famílias foram responsáveis por mais da metade da riqueza de trepadeiras encontrada na área (54\%), o que corrobora com a afirmação de que o hábito trepador apresenta ampla diversificação em poucos grupos vegetais (Gentry 1991). A maior riqueza de Apocynaceae e Asteraceae foi também encontrada em outros levantamentos realizados no RS, nas fitofisionomias da Floresta Estacional Semidecidual e Floresta Ombrófila Mista (Venturi 2000, Durigon \& Waechter 2011, Seger \& Hartz 2014).

Mikania (Asteraceae) e Ipomoea (Convolvulaceae) são dois dos gêneros com maior número de espécies trepadeiras no mundo (Gentry 1991). Ambos os gêneros apresentam também espécies de hábito arbustivo, apesar de serem menos diversificadas. No RS, ocorrem 33 espécies de Mikania de hábito trepador (Ritter et al. 2020) e 27 de Ipomoea (Simão-Bianchini et al. 2020). Esses representam os maiores gêneros de plantas trepadeiras no estado (Durigon et al. 2019). Em nível nacional, Mikania é o gênero com maior número de trepadeiras em Asteraceae, totalizando 150 das 199 trepadeiras nativas da família no Brasil (Ritter et al. 2020). As espécies habitam desde interior de florestas úmidas até campos e savanas (Ritter \& Miotto 2005). Ipomoea é o gênero mais rico em espécies trepadeiras da família Convolvulaceae, com 132 das 159 espécies nativas no Brasil (Simão-Bianchini et al. 2020). As espécies ocorrem, sobretudo, em bordas de mata, clareiras e áreas abertas, podendo apresentar comportamento ruderal (Ferreira \& Miotto 2009).

Os gêneros Passiflora (Passifloraceae) e Oxypetalum (Apocynaceae) possuem o terceiro maior número de trepadeiras no RS, com 19 espécies cada (Durigon et al. 2019; Bernacci et al. 2020). Passiflora, junto com Ipomoea, foi o gênero com o segundo maior número de espécies encontradas no JBPA (cinco cada), enquanto Oxypetalum apresentou apenas uma espécie. Passiflora é um gênero que apresenta algumas espécies comumente cultivadas devido a seus frutos ( $P$. alata e $P$. edulis), de modo que $P$. alata é por vezes citada como subespontânea (Bernacci et al. 2020), ocorrendo comumente em áreas com algum grau de antropização.

Dentre a riqueza de Bignoniaceae e Fabaceae na área de estudo, é interessante notar que cada espécie encontrada pertence a um gênero distinto. Isso provavelmente se deve à distribuição mais homogênea da riqueza específica de trepadeiras nos diferentes gêneros dessas famílias. No RS, há 12 gêneros e 24 espécies de Bignoniaceae trepadeiras, sendo o mais rico Dolichandra (cinco espécies), enquanto em Fabaceae há 25 gêneros e 58 espécies, com o mais rico sendo Lathyrus (nove espécies) (Durigon et al. 2019).

Considerando que Porto Alegre é uma cidade de confluência de floras de diferentes origens (Rambo 1954, Porto et al. 1998), compreende-se a riqueza semelhante de trepadeiras herbáceas e lenhosas (42 e 39 espécies) encontrada na área de estudo. As trepadeiras herbáceas ocorrem predominantemente nas formações abertas do Rio Grande do Sul, em campos rochosos e bordas de mata. Assim sendo, sua diversidade no estado concentra-se principalmente no bioma Pampa e nos campos de altitude da Mata Atlântica (Durigon et al. 2014). As lianas, por sua vez, ocupam formações florestais, dependendo de maior precipitação e de suportes mais robustos. Além disso, são intolerantes ao frio por possuírem vasos condutores de maior calibre, o que as torna vulneráveis a sofrerem embolia (Davis et al. 1999). Desse modo, são muito diversificadas em regiões tropicais, apresentando maior riqueza na metade norte do estado, onde elementos florísticos de origem atlântica e tropical atingem sua distribuição mais austral, através da "Porta de Torres" e da Bacia do Paraná, respectivamente (Rambo 1950, Rambo 1961). 
A prevalência de espécies volúveis em relação a outros mecanismos de escalada concorda com outros trabalhos realizados no Rio Grande do Sul (Durigon et al. 2009, Seger \& Hartz 2014, Guerra et al. 2015). A maior representatividade de espécies volúveis está relacionada ao fato de que grande parte das trepadeiras nativas no RS pertence às famílias Fabaceae, Apocynaceae, Asteraceae e Convolvulaceae, cujas espécies são, em sua maioria, volúveis (Durigon et al. 2019). Fabaceae apresenta também muitas espécies gavinhosas dos gêneros Lathyrus e Vicia, contudo, raramente são citadas nos levantamentos envolvendo trepadeiras, por serem gêneros que habitam áreas campestres, as quais são pouco abrangidas nos estudos com o grupo. Não foram registradas espécies nativas radicantes no presente estudo, apenas uma espécie exótica (Hedera helix). Durigon et al. (2013) relacionam a ocorrência de espécies radicantes a locais com elevados níveis de pluviosidade com baixa sazonalidade, como as florestas ombrófilas, o que não se aplica adequadamente às florestas da área de estudo, que são tipicamente estacionais.

A relação de interdependência entre os atributos hábito e mecanismo de escalada pode ser percebida no predomínio de espécies apoiantes que são lenhosas (91\%) e de volúveis que são herbáceas $(66 \%)$. O mecanismo radicante não é relevante neste caso, pois se trata apenas de uma espécie que o apresenta. A constatação de que o mecanismo apoiante é prevalente em lianas pode estar associado ao fato dessas possuírem vasos condutores maiores e mais calibrosos que as trepadeiras herbáceas (Ewers et al. 1991), possibilitando uma maior sustentação por essas plantas que não dispõem de nenhuma especialização externa para auxiliar na escalada. Deve-se ter cautela, contudo, ao generalizar a associação encontrada entre esses atributos a outras comunidades de trepadeiras, pois ela é altamente dependente do tamanho da amostra. Amostras de tamanhos diversos da avaliada neste trabalho podem mostrar resultados distintos, por isso há necessidade de mais estudos envolvendo essas associações.

A síndrome de dispersão mais frequente é a anemocoria, seguida pela zoocoria, barocoria e autocoria, respectivamente. A avaliação desse atributo funcional também se mostra concordante com outros levantamentos de trepadeiras realizados no RS, nos quais a anemocoria é a síndrome predominante, seguida pela zoocoria (Venturi 2000, Seger \& Hartz 2014). Para as espécies da área de estudo, hábito e síndrome de dispersão não são atributos interdependentes, apesar de existir um padrão no que se refere às espécies autocóricas, que são todas herbáceas. A autocoria está associada à deiscência dos legumes de gêneros herbáceos, como Lathyrus, Macroptilium, Vigna s.l. Os gêneros lenhosos Canavalia, e Macropsychanthus, contudo, apresentam dispersão barocórica, que certamente é um mecanismo mais eficiente para as plantas que se desenvolvem em maiores alturas na floresta do que para plantas habitantes do sub-bosque, pois acabam por conseguir dispersar suas sementes em grandes distâncias, apesar de não dispor de adaptações específicas para esse fim.

Foram registradas oito espécies exóticas na área de estudo, destas Hedera helix (Araliaceae), Podranea ricasoliana (Bignoniaceae) e Bougainvillea spectabilis (Nyctaginaceae) são ornamentais e foram encontradas isoladamente em poucas áreas do parque, onde provavelmente foram plantadas há muito tempo, bem como Dioscorea bulbifera (Dioscoreaceae), encontrada em apenas um ponto próximo a um acesso, que é utilizada como medicinal e alimentícia. Vicia angustifolia (Fabaceae) é ruderal e foi registrada em áreas campestres do parque. Thunbergia alata (Acanthaceae), Lonicera japonica (Caprifoliaceae) e Asparagus setaceus (Asparagaceae) são espécies exóticas invasoras no RS (SEMA 2013). Thumbergia alata e L. japonica foram registradas em poucos pontos próximos a cercas onde, talvez, também tenham sido plantadas como ornamentais, já A. setaceus, o aspargo-samambaia, trata-se de uma espécie invasora vigorosa e de difícil controle, que se desenvolve no interior de florestas secundárias, dominando o solo com seu rizoma, onde forma um emaranhado com seus finos cladódios e inibe o desenvolvimento de espécies que poderiam se estabelecer na área.

As trepadeiras distribuem-se no JBPA principalmente nas áreas abertas de vegetação campestre e nas bordas dos fragmentos florestais, sendo menos frequentes no interior dessas áreas, fato relacionado à dominância de Asparagus setaceus. Periodicamente é feito o controle dessa espécie em alguns pontos do parque com roçadas e retiradas manuais, mas é necessário elaborar uma medida mais efetiva de controle.

Cabe destaque o grande número de espécies encontradas dentro dos limites da Zona de Conservação in situ, na qual ocorrem 49 espécies, o que representa $60 \%$ da riqueza de trepadeiras do JBPA, sendo nove encontradas exclusivamente ali - Mandevilla pentlandiana, Orthosia urceolata e Oxypetalum wightianum (Apocynaceae), Fridericia chica (Bignoniaceae), Convolvulus crenatifolius (Convolvulaceae), Dioscorea multiflora (Dioscoreaceae), Heteropterys aenea e $H$. syringifolia (Malpighiaceae) e Anchietea pyrifolia (Violaceae). O principal problema para a conservação dessa área é a invasão por Pinus spp., outro gênero exótico e invasor (SEMA 2013), ocorrente em áreas lindeiras ao JBPA. Dresseno \& Overbeck (2013), em levantamento fitossociológico do relicto de campo localizado dentro da Zona, encontraram Pinus spp. em $73 \%$ das parcelas, com uma densidade de 4,6 indivíduos/ $\mathrm{m}^{2}$. É realizado manejo quinzenal para retiradas das mudas estabelecidas, e tratativas estão em andamento com os proprietários das áreas adjacentes para retirada das plantasmatrizes.

Com relação aos trabalhos realizados anteriormente no JBPA, houve um incremento muito expressivo na riqueza de trepadeiras da área. Entretanto, alguns táxons apontados não foram observados durante o presente estudo. Das 16 espécies citadas por Bueno \& Martins (1986), Vicia graminea Sm. (Fabaceae) e Mikania parodii (Asteraceae) não foram encontradas. Além disso, o material-testemunho de $V$. graminea não foi localizado, por isso a espécie não foi incluída. Mikania parodii teve seu material-testemunho verificado por especialista. Acreditamos que não foi possível 
encontrar essas espécies, pois os locais de coleta foram alterados para a construção dos lagos hoje existentes na área. Dresseno \& Overbeck (2013) citaram 13 táxons de trepadeiras e Galactia gracilima Benth. (Fabaceae) não foi encontrada durante a realização deste estudo. Como o material-testemunho não foi localizado, a espécie também não foi incluída.

Em um primeiro momento, um dos objetivos do presente estudo era analisar a similaridade florística entre o JBPA e outros sítios onde levantamentos de trepadeiras foram realizados no RS. Porém, grande parte dos trabalhos foi desenvolvida em áreas florestais, sem ou com pouca influência antrópica (Venturi 2000, Durigon \& Waechter 2011) ou em Unidades de Conservação (Seger \& Hartz 2014, Seger et al. 2017) e mesmo quando realizados em áreas antropizadas (Durigon et al. 2009), as espécies exóticas e/ou invasoras não são citadas e não há referência sobre essa questão, gerando dúvidas se realmente essas espécies não ocorrem nas áreas amostradas ou se foram excluídas da listagem final. Moro et al. (2012) relatam que esse é um problema frequente em trabalhos de florística e que, com isso, perde-se a oportunidade de saber quais são e onde estão as espécies exóticas e/ou invasoras que ocupam dada região. Apresentar o registro dessas espécies nos artigos de florística (e nas coletas depositadas em herbário que devem acompanhar esses artigos) torna possível mapear a sua distribuição, informação que é perdida se essas plantas são intencionalmente subamostradas. Pelo exposto, não foi possível analisar a similaridade entre as áreas, pois os dados obtidos não seriam fidedignos. Apenas Guerra et al. (2015) citaram e analisaram a ocorrência das espécies exóticas amostradas na área de estudo.

Levantamentos florísticos são importantes estudos de reconhecimento da flora de determinado local, retratando a composição dos táxons em determinada época. No Rio
Grande do Sul, há lacunas de informação referentes às plantas trepadeiras principalmente em determinadas regiões do estado, como no bioma Pampa, que vem se mostrando especialmente rico em espécies de trepadeiras herbáceas (Durigon et al. 2019), e na Floresta Ombrófila Densa, que não apresenta nenhum levantamento exclusivo com o grupo até o momento, apesar de sua notória importância como limite austral de distribuição de muitos táxons oriundos do contingente florístico atlântico (Rambo 1961).

Apesar dos diversos serviços ecossistêmicos oferecidos pelas áreas verdes urbanas, através das diferentes funções que desempenham na melhoria da qualidade de vida das pessoas (Bargos \& Matias 2011), ainda são escassos os estudos envolvendo a biodiversidade dessas áreas. O futuro das cidades deve estar ancorado em valores de conservação ambiental, que deve ser central no planejamento urbano. A Ecologia Urbana levanta questões importantes que devem ser consideradas para responder de que maneira a urbanização afeta a biodiversidade e os processos ecológicos associados a ela, orientando a estruturação do ambiente urbano de maneira sustentável (McPhearson et al. 2016). O ponto de partida para a disseminação de valores de conservação ambiental em qualquer escala é a geração de conhecimento a respeito da biodiversidade, pois só é possível conservar aquilo que conhecemos.

O Jardim Botânico de Porto Alegre abriga pelo menos $16 \%$ das espécies de plantas trepadeiras nativas no Rio Grande do Sul, o que é muito significativo dada a pequena extensão da área. Considerando sua relevância como instituição de pesquisa e de conservação da flora nativa, bem como sua atuação direta na educação ambiental da população, o JBPA pode ser considerado uma das mais importantes áreas verdes do município, cabendo ao Poder Público a sua manutenção e perpetuação.

\section{Chaves baseadas em caracteres vegetativos para identificação das plantas trepadeiras de ocorrência espontânea no Jardim Botânico de Porto Alegre}

\section{Índice para as chaves de identificação}

1. Plantas com gavinhas ou raízes adesivas.

2. Folhas compostas Chave 1

2. Folhas simples Chave 2

1'. Plantas volúveis ou apoiantes, com ou sem acúleos/espinhos.

3. Folhas compostas Chave 3

3'. Folhas simples.

4. Filotaxia alterna ou geminada Chave 4

4'. Filotaxia oposta.

5. Plantas com látex Chave 5

5'. Plantas sem látex Chave 6 


\section{Chave 1 - Plantas com gavinhas ou raízes adesivas, folhas compostas}

1. Folhas digitadas

Clematicissus striata

1'. Folhas bifolioladas, trifolioladas, pinadas ou biternadas.

2. Folhas trifolioladas ou bifolioladas com folíolo central modificado em gavinha.

3. Trepadeiras herbáceas com folíolos lineares; estípulas sagitadas

Lathyrus crassipes

3'. Trepadeiras lenhosas com folíolos lanceolados ou ovados; estípulas ausentes (pode haver presença de profilos axilares de outros formatos).

4. Gavinhas trífidas uncinadas Dolichandra unguis-cati

4'. Gavinhas espiraladas simples ou ramificadas.

5. Ramos costados; gavinhas ramificadas.

6. Folíolos largo-ovados, base cordada; profilos axilares foliáceos; caule lenhoso maduro marcadamente costado Amphilophium crucigerum

6'. Folíolos ovados, base obtusa; profilos axilares inconspícuos; caule lenhoso maduro com ritidoma se desprendendo em placas

Pyrostegia venusta

5'. Ramos não costados, gavinhas simples.

7. Folíolos lanceolados; profilos axilares inconspícuos; coloração cobre quando herborizada Fridericia chica

7’. Folíolos ovados; profilos axilares foliáceos; sem coloração característica quando herborizada

Tanaecium selloi

2'. Folhas biternadas, pinadas ou quando trifolioladas com gavinhas axilares; gavinhas axilares ou folíolo terminal modificado em gavinha.

8. Folhas pinadas com folíolo terminal modificado em gavinha

Vicia angustifolia

8. Folhas biternadas, trifolioladas ou pinadas; gavinhas axilares.

9. Folhas biternadas.

10. Trepadeiras lenhosas; presença de látex branco; folíolos cartáceos; presença frequente de domácias ...

Serjania laruotteana

10'. Trepadeiras herbáceas; ausência de látex; folíolos membranáceos; ausência de domácias

. Cardiospermum halicacabum

9'. Folhas imparipinadas ou trifolioladas.

11. Folhas imparipinadas, com 5(-7) folíolos; trifolioladas quando jovem, folíolo central mais alongado que os laterais Paullinia elegans

11'. Folhas trifolioladas, com os folíolos de mesmo tamanho Serjania hebecarpa

\section{Chave 2 - Plantas com gavinhas ou raízes adesivas, folhas simples}

1. Raízes adesivas como mecanismo de escalada Hedera helix*

1'. Gavinhas como mecanismo de escalada.

2. Presença de acúleos.

3. Margem da folha espessada Smilax cognata

3'. Margem da folha não espessada Smilax campestris

2’. Ausência de acúleos.

4. Gavinhas opostas às folhas.

5. Folhas inteiras, margem serreada, base sagitada; raízes adventícias avermelhadas Cissus verticillata

5 '. Folhas lobadas, margem inteira ou denteada. 
6. Folhas palmatipartidas Cayaponia martiana

6. Folhas trilobadas a palmatífidas Melothria cucumis

4'. Gavinhas axilares.

7. Folhas inteiras; caule quadrangular Passiflora alata

7'. Folhas trilobadas, às vezes com o lobo central inconspícuo; caule cilíndrico.

8. Estípulas foliáceas reniformes Passiflora tenuifila

8'. Estípulas lineares a lanceoladas.

9. Folhas com margem serreada Passiflora edulis

9'. Folhas com margem inteira.

10. Folhas com os lobos laterais muito maiores que o central (formato "asa-delta"); presença de glândulas no limbo e ausência no pecíolo Passiflora misera

10'. Folhas com os lobos de tamanho semelhante ou com o central maior que os laterais; ausência de glândulas no limbo e presença de um par no pecíolo Passiflora suberosa

\section{Chave 3 - Plantas volúveis ou apoiantes, folhas compostas}

1. Folhas pinadas ou digitadas.

2. Folhas digitadas, presença de acúleos Rubus urticifolius

2 '. Folhas pinadas, plantas inermes Podranea ricasoliana*

1'. Folhas trifolioladas.

3. Folíolos com margem inteira.

4. Ramos e pecíolos hirsutos; estípulas maiores do que $1 \mathrm{~cm}$ de comprimento ..... Macropsychanthus violaceus

4. Ramos glabrescentes; estípulas menores do que $1 \mathrm{~cm}$ de comprimento.

5. Folíolos ovado-romboidais Leptospron adenanthum

5'. Folíolos ovado-elípticos ou oblongos.

6. Trepadeiras lenhosas; folíolos ovado-elípticos, maiores do que $4 \mathrm{~cm}$ de comprimento, com tricomas distribuídos homogeneamente pelo limbo; estípulas com 1 a $2 \mathrm{~mm}$ de comprimento

Canavalia bonariensis

6'. Trepadeiras herbáceas; folíolos oblongos ou elípticos, menores do que $4 \mathrm{~cm}$ de comprimento, com tricomas somente sobre as nervuras; estípulas maiores do que $2 \mathrm{~mm}$ Macroptilium prostratum

3'. Folíolos com margem denteada Dalechampia stenosepala

\section{Chave 4 - Plantas volúveis ou apoiantes, folhas simples, filotaxia alterna ou geminada}

1. Plantas áfilas, presença de cladódios pinatissectos Asparagus setaceus*

1'. Plantas com folhas.

2. Folhas palmatipartidas ou palmatissectas.

3. Pecíolos alongados, volúveis Tropaeolum pentaphyllum

3’. Ramos volúveis.

4. Planta glabra; folhas palmatissectas; pseudoestípulas semelhantes às folhas Ipomoea cairica 4'. Ramos e pecíolos hirsutos, folhas palmatipartidas a palmatissectas, pseudoestípulas ausentes 
2'. Folhas com margem inteira, serreada ou denteada.

5. Folhas com nervação actinódroma ou campilódroma.

6. Plantas com pseudoestípulas amplexicaules Aristolochia triangularis

6'. Plantas sem estípulas.

7. Folhas com ápice arredondado, reniformes, levemente peltadas

Cissampelos pareira

7'. Folhas com ápice acuminado, base cordada a sagitada, não peltadas.

8. Folhas com margem inteira, nervação campilódroma.

9. Folhas com nervuras secundárias impressas na face adaxial; presença de tubérculos laterais

Dioscorea bulbifera*

9'. Folhas com nervuras secundárias pouco evidentes na face adaxial; ausência de tubérculos laterais

Dioscorea multiflora

8'. Folhas com margem serreada ou denteada, nervação actinódroma

Tragia volubilis

5'. Folhas com outros tipos de nervação.

10. Plantas apoiantes.

11. Folhas trinervadas, margem crenada a denteada

Baccharis anomala

11'. Folhas com uma única nervura partindo da base, margem inteira.

12. Folhas crassas e glabras Pereskia aculeata

12'. Folhas membranáceas e pilosas Bougainvillea spectabilis*

10'. Plantas volúveis.

13. Estípulas unidas formando ócrea Muehlenbeckia sagittifolia 13'. Plantas sem estípulas.

14. Pecíolos alongados, volúveis Solanum laxum

14'. Ramos volúveis.

15. Folhas cordiformes.

16. Folhas crassas com nervação pouco evidente; presença de tubérculos laterais Anredera cordifolia

16'. Folhas membranáceas com nervação evidente.

17. Plantas glabras, acúleos verrucosos nos ramos Ipomoea alba

17'. Plantas pilosas, ramos inermes.

18. Indumento seríceo a esparso-pubescente, glabrescente; nectários ou glândulas presentes na inserção do pecíolo com a lâmina foliar.

19. Indumento seríceo; glândulas sésseis e brilhantes agrupadas na base das folhas Ipomoea indica

19'. Indumento esparso-pubescente, glabrescente; nectários em depressões na base das folhas Ipomoea triloba

18'. Indumento hirsuto; glândulas ausentes na inserção do pecíolo com a lâmina foliar Ipomoea nil

15'. Folhas elípticas com base aguda, sagitada ou hastada.

20. Plantas glabras; folhas com margem serreada e base aguda Anchietea pyrifolia

20'. Plantas pubescentes; folhas com margem ondulada a crenada (raro inteira), base sagitada ou hastada Convolvulus crenatifolius 


\section{Chave 5 - Plantas volúveis ou apoiantes, folhas simples, filotaxia oposta, com látex}

1. Plantas frequentemente áfilas; folhas, quando presentes, uninervadas Orthosia scoparia

1'. Plantas nunca áfilas; folhas com nervação secundária evidente.

2. Folhas discolores.

3. Folhas pilosas, sobretudo na face abaxial.

4. Coléteres presentes nos nós Mandevilla pentlandiana

4'. Coléteres presentes na base da nervura central, na face adaxial da folha.

5. Folhas de base sagitada ou cordada; nervuras secundárias divergindo a $45^{\circ}$ da primária; pecíolo de tamanho similar ao limbo; odor marcante Gonolobus parviflorus

5'. Folhas de base truncada a levemente sagitada, de formato deltóide; nervuras secundárias divergindo a mais de $45^{\circ}$ com a primária; pecíolo menor que o limbo; sem odor marcante Araujia sericifera

3'. Folhas completamente glabras.

6. Folhas de base cordada; mais de 10 pares de nervuras secundárias, bem visíveis; espécie associada a ambientes úmidos (banhados, lagos) Rhabdadenia madida

6'. Folhas de base cuneada ou truncada; 3-4 pares de nervuras secundárias, pouco visíveis; não associada a ambientes úmidos Orthosia urceolata

2'. Folhas concolores.

7. Ramos floríferos com folhas menores que os ramos estéreis; folhas com 0,5 a $4,5 \mathrm{~cm}$ de comprimento Ditassa burchellii

7'. Ramos floríferos e estéreis com folhas de tamanhos similares.

8. Folhas de base cordada ou sagitada; ramos tomentosos Oxypetalum wightianum

8 '. Folhas de base aguda ou obtusa; ramos glabros.

9. Folhas elípticas a obovadas, frequentemente com domácias; ramos lenticelados; trepadeiras lenhosas.

10. Folhas elípticas a ovado-elípticas, base frequentemente cuneada; domácias glabras; ramos com lenticelas bem marcadas, esbranquiçadas Forsteronia glabrescens

10’. Folhas elípticas a obovadas, base arredondada; domácias pilosas; ramos com lenticelas pouco marcadas Forsteronia leptocarpa

9’. Folhas lanceoladas, sem domácias; ramos sem lenticelas; trepadeiras herbáceas

Orthosia virgata

\section{Chave 6 - Plantas volúveis ou apoiantes, folhas simples, filotaxia oposta, sem látex}

1. Presença de glândulas (nectários extraflorais) no pecíolo e/ou no limbo foliar.

2. Folhas com a face abaxial marcadamente dourada Heteropterys aenea

2'. Folhas concolores, ou pouco discolores.

3. Par de glândulas na base do pecíolo Heteropterys intermedia

3'. Glândulas nunca na base do pecíolo, quando presentes ocorrem na região apical e/ou no limbo foliar.

4. Trepadeiras lenhosas; ramos e folhas glabros; pecíolos avermelhados nas folhas jovens Heteropterys syringifolia

4'. Trepadeiras herbáceas; ramos e folhas tomentosos; pecíolos não avermelhados Janusia guaranitica

1'. Ausência de glândulas.

5. Presença de estípulas.

6. Plantas com acúleos; arvoretas apoiantes. 
7. Folhas glabras, trinervadas; ramificação dicotômica Strychnos brasiliensis

7'. Folhas pilosas, com uma única nervura partindo da base; ramificação não dicotômica Guettarda uruguensis

6'. Plantas inermes; subarbustos ou arbustos apoiantes.

8. Estípulas do mesmo tamanho do par de folhas opostas (aspecto verticilado) Galium hypocarpium 8 '. Estípulas lineares, bem menores que o par de folhas Chiococca alba 5'. Ausência de estípulas.

9. Arbustos ou arvoretas apoiantes.

10. Folhas com margem inteira; lenticelas nos ramos Guettarda uruguensis

$10^{\prime}$. Folhas com margem crenada a serreada; sem lenticelas.

11. Folhas trinervadas; cinco ou menos pares de dentes Calea pinnatifida

11'. Folhas com uma única nervura partindo da base; mais de cinco pares de dentes Lantana camara 9’. Trepadeiras volúveis.

12. Folhas de nervação peninérvea Lonicera japonica* 12'. Folhas de nervação palmatinérvea.

13. Folhas com pecíolo alado Thunbergia alata* 13'. Folhas com pecíolo sem alas.

14. Ramos hexagonais Mikania cordifolia

14'. Ramos cilíndricos.

15. Folhas lanceoladas de base cuneada Mikania laevigata $15^{\prime}$. Folhas com outros formatos.

16. Folhas deltóides de base truncada ou levemente cordada; ramos jovens avermelhados Mikania involucrata

16'. Folhas ovaladas de base sagitada ou cordada; ramos não avermelhados.

17. Folhas de margem inteira.

18. Trepadeira herbácea; folhas de consistência membranácea, até $6 \mathrm{~cm}$ de comprimento ... Mikania hastato-cordata

18'. Trepadeira lenhosa; folhas de consistência coriácea, $624 \mathrm{~cm}$ de comprimento Mikania glomerata

17’. Folhas de margem denteada ou crenada.

19. Ramos e folhas pilosos, margem denteada Mikania micrantha 19'. Ramos e folhas glabros ou esparso pilosos, margem denteada ou crenada Mikania parodii 


\section{AGRADECIMENTOS}

Ao CNPq pela bolsa de Iniciação Científica concedida ao primeiro autor, aos funcionários e bolsistas do JBPA e do MCN pelo apoio e amizade. À Dra. Jaqueline Durigon pelas valiosas sugestões. Aos especialistas consultados pelo auxílio na identificação das espécies: MSc. Angelo Massing, Dra. Cristiane Snak, MSc. Dilana da Silva, Dr. Guilherme Seger, Dra. Mara Ritter e Dra. Silvia Miotto.

\section{REFERÊNCIAS}

APG IV. 2016. An update of the Angiosperm Phylogeny Group classification for the orders and families of flowering plants. Botanical Journal of the Linnean Society 181(1):1-20.

Bargos, D.C. \& Matias, L.F. 2011. Áreas verdes urbanas: um estudo de revisão e proposta conceitual. Revista da Sociedade Brasileira de Arborização Urbana 6(3):172-188.

Barnosky, A.D., Matzke, N., Tomiya, S., Wogan, G.O.U., Swartz, B., Quental, T.B., Marshall, C., McGuire, J.L., Lindsey, E.L., Maguire, K.C., Mersey, B. \& Ferrer, E.A. 2011. Has the Earth's sixth mass extinction already arrived? Nature 471:51-57.

Bernacci, L.C., Nunes, T.S., Mezzonato, A.C., Milward-de-Azevedo, M.A., Imig, D.C. \& Cervi, A.C. (in memoriam). 2020. Passiflora. In Flora do Brasil 2020. Jardim Botânico do Rio de Janeiro. Disponível em: <http://floradobrasil.jbrj.gov.br/reflora/floradobrasil/FB12508>. Acessado em: 07.08.2021

Bueno, O.L. \& Martins, S.M.A. 1986. A flora e vegetação espontânea do Jardim Botânico de Porto Alegre, RS, Brasil. Fanerógamas herbáceas e arbustivas. Iheringia. Série Botânica 35:5-23.

Carneiro, J.S. \& Vieira, A.O.S. 2012. Trepadeiras: florística da Estação Ecológica do Caiuá e chave de identificação vegetativa para as espécies do Norte do Estado do Paraná. Acta Scientiarum 34(2):217223.

Carrasco-Urra, F. \& Gianoli, E. 2009. Abundance of climbing plants in a southern temperate rain forest: host tree characteristics or light availability? Journal of Vegetation Science 20:1155-1162.

Darwin, C. 1865. On the movements and habits of climbing plants. Botanical Journal of the Linnean Society 9:1-118.

Davis, S., Sperry, J. \& Hacke, U. 1999. The relationship between xylem and cavitation caused by freezing. American Journal of Botany 86:1367-1372.

Dresseno, A.L.P. \& Overbeck, G.E. 2013. Estrutura e composição de um relicto de vegetação campestre em uma matriz urbana: potencial e desafios para a conservação. Iheringia. Série Botânica 68(1):59-71.

Durigon, J., Canto-Dorow, T.S. \& Eisinger, S.M. 2009. Composição florística de trepadeiras ocorrentes em fragmentos de floresta estacional, Santa Maria, Rio Grande do Sul, Brasil. Rodriguésia 60(2):415-422.

Durigon, J. \& Waechter, J.L. 2011. Floristic composition and biogeographic relations of a subtropical assemblage of climbing plants. Biodiversity and Conservation 20(5):1027-1044.

Durigon, J., Durán, S.M. \& Gianoli, E. 2013. Global distribution of root climbers is positively associated with precipitation and negatively associated with seasonality. Journal of Tropical Ecology 29(4):357360.

Durigon, J., Miotto, S.T.S., \& Gianoli, E. 2014. Distribution and traits of climbing plants in subtropical and temperate South America. Journal of Vegetation Science 25(6):1484-1492.

Durigon, J., Sperotto, P., Ferreira, P.P.A., Dettke, G.A., Záchia, R.A., Farinaccio, M.A., Seger, G.D.S. \& Miotto, S.T.S. 2019. Updates on extratropical region climbing plant flora: news regarding a stillneglected diversity. Acta Botanica Brasilica 33(4):644-653.

Ewers, F.W., Fisher, J.B. \& Fichtner, K. 1991. Water flux and xylem structure in vines. In The Biology of Vines (F.E. Putz \& H.A. Mooney, eds.). Cambridge University Press, Cambridge, p. 127-160.

Flora do Brasil. 2020. Jardim Botânico do Rio de Janeiro. Disponível em: http://floradobrasil.jbrj.gov.br. Acessado em 06.08.2021.
Ferreira, P.P.A. \& Miotto, S.T.S. 2009. Sinopse das espécies de Ipomoea L. (Convolvulaceae) ocorrentes no Rio Grande do Sul, Brasil. Revista Brasileira de Biociências 7(4):440-453.

Filgueiras, T.S., Nogueira, P.E., Brochado, A.L. \& Guala II, G.F. 1994. Caminhamento: um método para levantamentos florísticos qualitativos. Cadernos de Geociências 12:39-43.

FZBRS. 2014. Plano Diretor do Jardim Botânico de Porto Alegre. Fundação Zoobotânica do Rio Grande do Sul, Porto Alegre, 2a ed. $106 \mathrm{p}$.

Gallagher, R.V. \& Leishman, M.R. 2014. A global analysis of trait variation and evolution in climbing plants. Journal of Biogeography 39:17571771 .

Gentry, A.H. 1991. The distribution and evolution of climbing plants. In The Biology of Vines (F.E. Putz \& H.A. Mooney, eds.). Cambridge University Press, Cambridge, p. 3-49.

Gentry, A.H. 1993. A Field Guide to the Families and Genera of Woody Plants of Northwest South America. (Colombia, Ecuador, Peru) with supplementary notes on herbaceous taxa. 1ed. The University of Chicago Press, Chicago and London. 920 p.

Guerra, E., Streher, N.S., Ludtke, R., 2015. Plantas trepadeiras do Horto Botânico Irmão Teodoro Luis, sul do Rio Grande do Sul, Brasil. Revista Brasileira de Biociências 13:201-209.

Hasenack, H., Cordeiro, J.L.P., Boldrini, I., Trevisan, R., Brack, P. \& Weber, E.J. 2008. Vegetação/ocupação. In Diagnóstico Ambiental de Porto Alegre: geologia, solos, drenagem, vegetação/ocupação e paisagem (Hasenack, H., ed.). Secretaria Municipal do Meio Ambiente, Porto Alegre, p. 56-71.

Hegarty, E.E. 1991. Vine-host interactions. In The Biology of Vines (F.E. Putz \& H.A. Mooney, eds.). Cambridge University Press, Cambridge, p. 357-375.

Heywood, V.H., Huang, H. \& Hu, Y. 2017. The future of plant conservation and the role of botanic gardens. Plant Diversity 39(6):309-313.

IBGE. 2012. Mapa da Área de Aplicação da Lei n ${ }^{\circ}$ 11.428/2006, alterada pelo Decreto $\mathrm{n}^{\circ} 6660 / 2008,2^{\mathrm{a}}$ ed. Instituto Brasileiro de Geografia e Estatística. Disponível em: http://geoftp.ibge.gov. br/informacoes_ambientais/estudos_ambientais/biomas/mapas/. Acessado em 05.12.2020.

INMET. 2019. Banco de Dados Meteorológicos para Ensino e Pesquisa. Instituto Nacional de Meteorologia. Disponível em: http://www.inmet. gov.br/portal/index.php?r=bdmep/bdmep. Acessado em 07.11.2019.

IPNI. 2020. International Plant Names Index. Disponível em: http:// www.ipni.org. Acessado em 05.12.2020.

Kottek, M., Grieser, J., Beck, C., Rudolf, B. \& Rubel, F. 2006. World Map of the Köppen-Geiger climate classification updated. Meteorologische Zeitschrift 15: 259-263.

Maxted, N., Ford-Lloyd, B. \& Hawkes, J.G. 1997. Complementary conservation strategies. In Plant Genetic Conservation: The In Situ Approach (N. Maxted, B. Ford-Lloyd, J.G. Hawkes, eds.). Chapman and Hall, London, p. 15-39.

McPhearson, T., Pickett, S.T.A., Grimm, N.B., Niemelã, J., Alberti, M., Elmqvist, T., Weber, C., Haase, D., Breuste, J. \& Qureshi, S. 2016. Advancing Urban Ecology toward a Science of Cities. BioScience 66(3):198-212.

MMA. 2003. Resolução CONAMA no 339/2003. Ministério do Meio Ambiente, Brasil. Disponível em: http://www.icmbio.gov.br/cepsul/ images/stories/legislacao/Resolucao/2003/res_conama_339_2003_ jardinsbotanicos.pdf. Acessado em 26.09.2020.

Moro, M.F.; Souza, V.C.; Oliveira-Filho, A.T.; Queiroz, L.P.; Fraga, C.N.; Rodal, M.J.N.; Araújo, F.S. \& Martins, F.R. 2012. Alienígenas na sala: o que fazer com espécies exóticas em trabalhos de taxonomia, florística e fitossociologia? Acta Botanica Brasilica 26(4): 991-999.

Oliveira-Gomes, L.C., Durigon, J., Padilha, P.T. \& Citadini-Zanette, V. 2018. Composição florística e estrutura da comunidade de trepadeiras da Floresta Atlântica no Sul de Santa Catarina, Brasil. Iheringia 73(1):5-12.

Pacheco, M.F.S.D. 1956. Divisão Regional do Rio Grande do Sul. Boletim Geográfico do Rio Grande do Sul 4:7-16.

Porto, M. L. 1998. As formações vegetais: evolução e dinâmica da conquista. In Atlas Ambiental de Porto Alegre (R. Menegat, M.L. Porto, C.C. Carraro \& L.L.D. Fernandes, eds.). Editora da Universidade Federal do Rio Grande do Sul, Porto Alegre, p. 47-58. 
Powledge, F. 2011. The Evolving Role of Botanical Gardens. BioScience 61(10):743-749.

QGIS. 2021. QGIS Geographic Information System. QGIS Association. Disponível em: http://www.qgis.org. Acessado em 19.01.2021.

R Development Core Team. 2018. R: A language and environment for statistical computing. Vienna, R Foundation for Statistical Computing. Disponível em: https://www.R-project.org. Acessado em 19.01.2021.

Rambo, B. 1950. A porta de Torres. Anais Botânicos do Herbário Barbosa Rodrigues 2: 9-20.

—. 1954. Análise histórica da flora de Porto Alegre. Sellowia 6:9-112.

—. 1961. Migration routes of the South Brazilian rain forest. Pesquisas 12:5-54.

REFLORA. 2021. Herbário Virtual Reflora. Disponível em: http:// floradobrasil.jbrj.gov.br/reflora/herbarioVirtual/. Acessado em 06.08.2021.

Ritter, M.R. \& Miotto, S.T.S. 2005. Taxonomia de Mikania Willd. (Asteraceae) no Rio Grande do Sul, Brasil. Hoehnea 32(3):309-359.

Ritter, M.R, Liro, R.M., Roque, N., Nakajima, J.N., Souza-Buturi, F.O. \& Oliveira, C.T. 2020. Mikania. In Lista de Espécies da Flora do Brasil. Jardim Botânico do Rio de Janeiro. Disponivel em: http:// floradobrasil.jbrj.gov.br/jabot/floradobrasil/FB27264. Acessado em 31.10.2020.

Rolim, R.G., Setubal, R.B., Casagrande, A., Rivas, M.I.E., Nardin, J.A., Proença, M.L., Sandri, S.M., Bonilha, C.L. \& Boldrini, I.I. 2014. Composição e estrutura de vegetação campestre em áreas com orientação norte e sul no Jardim Botânico de Porto Alegre, RS, Brasil. Iheringia. Série Botânica 69(2):433-449.

Rio Grande do Sul. 2003. Lei Estadual no 11.917/2003. Disponível em:

http://www.al.rs.gov.br/filerepository/repLegis/arquivos/11.917.pdf. Acessado em 26.09.2020.

Schnitzer, S.A. \& Bongers, F. 2002. The ecology of lianas and their role in forests. Trends in Ecology \& Evolution 17:223-230.

Schnitzer, S.A. 2005. A mechanistic explanation for global patterns of liana abundance and distribution. The American Naturalist 166:262-276.

Seger, G.D.S.; Hartz, S.M. 2014. Checklist of climbing plants in an Araucaria forest of Rio Grande do Sul State, Brazil. Biota Neotropica 14:1-12.

Seger, G. D. S., Cappelatti, L., Gonçalves, L. O., Becker, F. G., Melo, A. S., \& Duarte, L. D. S. 2017. Phylogenetic and functional structure of climbing plant assemblages in woody patches advancing over Campos grassland. Journal of Vegetation Science 28(6):1187-1197.

SEMA. 2013. Portaria SEMA n ${ }^{\circ} 79 / 2013$. Secretaria Estadual do Meio Ambiente, Porto Alegre. Disponível em: https://www.sema.rs.gov. br/upload/arquivos/201612/23180118-portaria-sema-79-de-2013especies-exoticas-invasoras-rs.pdf. Acessado em 26.09.2020.

Setubal, R.B., Boldrini, I.I., Ferreira, P.M.A. 2011. Campos dos morros de Porto Alegre. Associação Sócio-Ambientalista Igré, Porto Alegre. $254 \mathrm{p}$.

Simão-Bianchini, R., Ferreira, P.P.A. \& Vasconcelos, L.V. 2020. Ipomoea. In Lista de Espécies da Flora do Brasil. Jardim Botânico do Rio de Janeiro. Disponivel em: http://floradobrasil.jbrj.gov.br/jabot/ floradobrasil/FB7021. Acessado em: 31.10.2020.

Soares, J.F \& Fagundes, N.F. 2020. Epífitos vasculares no Jardim Botânico de Porto Alegre, Brasil - Flora epifítica vascular nativa espontânea no Jardim Botânico de Porto Alegre, Rio Grande do Sul, Brasil. Field Guides 1214. Chicago: Field Museum. Disponível em: https://fieldguides.fieldmuseum.org/guides/guide/1214. Acessado em 06.05.2020.

speciesLink 2021. speciesLink Network. Disponível em: https:// specieslink.net/search/. Acessado em: 06.08.2021

Sperotto, P., Acevedo-Rodríguez, P., Vasconcelos, T.N.C. \& Roque, N. 2020. Towards a Standardization of Terminology of the Climbing Habit in Plants. The Botanical Review 86:180-210.

Tanner, C.J., Adler, F.R., Grimm, N.B., Groffman, P.M., Levin, S.A., Munshi-South, J., Pataki, D.E., Pavao-Zuckerman, M. \& Wilson, W.G. 2014. Urban ecology: advancing science and Society. Frontiers in Ecology and Environment 12(10):574-581.

Udulutsch, R.G., Souza, V.C., Rodrigues, R.R. \& Dias, P. 2010. Composição florística e chaves de identificação para as lianas da Estação Ecológica dos Caetetus, estado de São Paulo, Brasil. Rodriguésia 61(4):715-730.

Van der Pijl, L. 1982. Ecological Dispersal Classes, Established on the Basis of the Dispersing Agents. In Principles of Dispersal in Higher Plants (L.van der Pijl, ed.). Springer-Verlag, Berlin Heidelberg New York, 3rd ed, p. 22-90.

Venturi, S. 2000. Florística e fitossociologia do componente apoianteescandente em uma floresta costeira subtropical. Dissertação 110 p., Universidade Federal do Rio Grande do Sul, Porto Alegre. 